MATEC Web of Conferences 10, 01001 (2014)

DOI: $10.1051 /$ matecconf/ 20141001001

(C) Owned by the authors, published by EDP Sciences, 2014

\title{
Experimental Research Methods for Students in Built Environment and Engineering
}

\author{
A.N. Abdul Ghani
}

School of Housing, Building and Planning, Universiti Sains Malaysia, 11800, Penang, Malaysia

\begin{abstract}
This paper describes the deductive approach to research in engineering and built environment and focuses mainly on the use of experiments for data gathering. Details of experimental methods in the laboratory, field and numerical conditions are discussed. Various sensors and transducers commonly used in experiments as well as data logging systems are also described.
\end{abstract}

\section{Introduction}

Research methodology is commonly acknowledged as the most important part of any research project that needs to be established before the actual data collection program begins. It is like a road map. Research methods and experimental techniques form the major portion of the methodology. In engineering and built environment, detail methodology and tasks to be carried out depends mainly on the type of data to be collected i.e. quantitative (numerical) or qualitative (describe by words). In certain conditions, qualitative data can still be converted to numerical data and analysed by quantitative methods. Another aspect of scientific research is the research approach, where the common approach could be inductive or deductive or both. Most researchers in applied science, engineering and the built environment prefer the deductive approach in which a problem is identified and then its cause and effect is confirmed by experimental data or proof. This paper describes the common methods of experiments and its data collection techniques.

\section{Experiments}

Experiments carried out for the purpose of collecting data to be analysed and studied are carried out in the laboratory, in the field or using computer numerical models. It also can be a combination of two or three of the said techniques [1]. The decision on the location of an experiment depends on the objectives and scope of the research. Each method has its own strengths, challenges and limitations as well as additional considerations to be included. For example, a laboratory scale model (Figure 1a) has to deal with scale and similitude issues. The field experiment involves a lot of variants and possible disturbances (Figure 1b). Computer simulation depends a lot on the input data (Figure 1c). Despite the limitations and possible problems, deductive experimental research techniques are preferable in the case of product, technique or technology focused research. This is because it is confirmatory in nature and has specific objectives rather than concepts and guesswork as in the inductive approach. It is also compatible to quantitative methods [2].

Corresponding author: anaser@usm.my

This is an Open Access article distributed under the terms of the Creative Commons Attribution License 2.0, which permits unrestricted use, distribution, and reproduction in any medium, provided the original work is properly cited. 


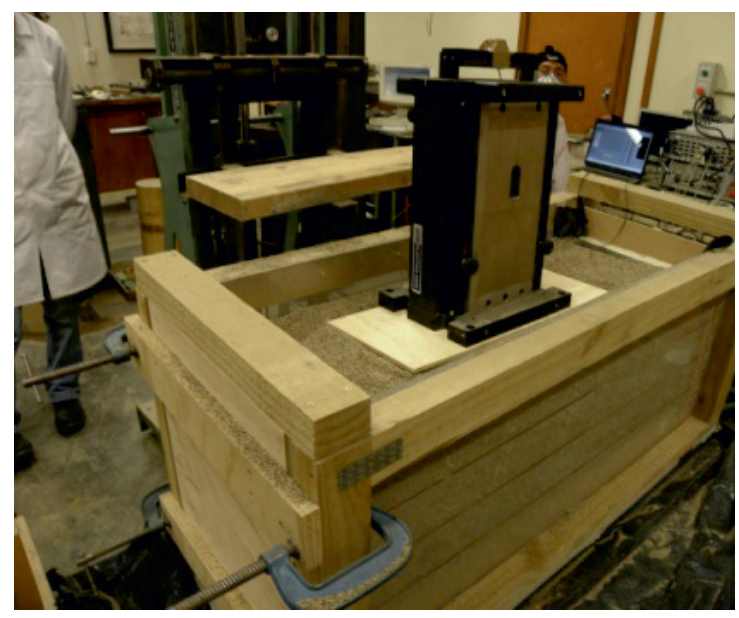

Figure 1a: Laboratory experiment

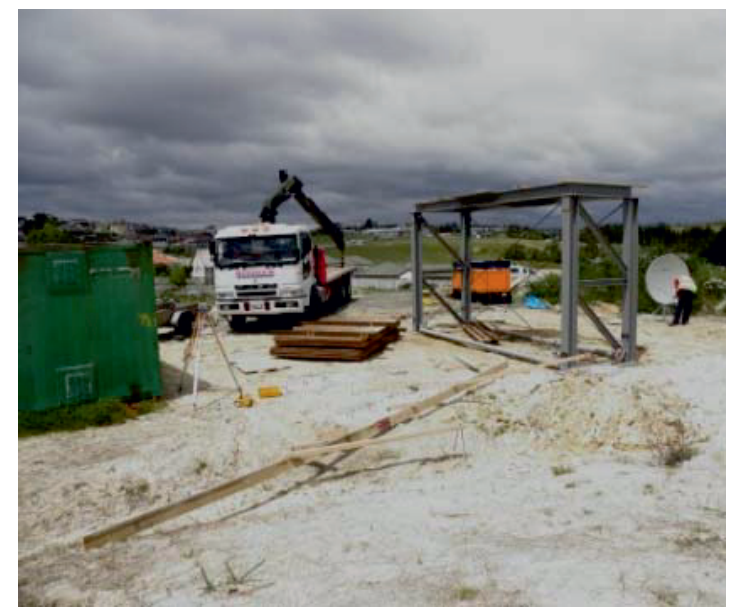

Figure 1b: Field experiment

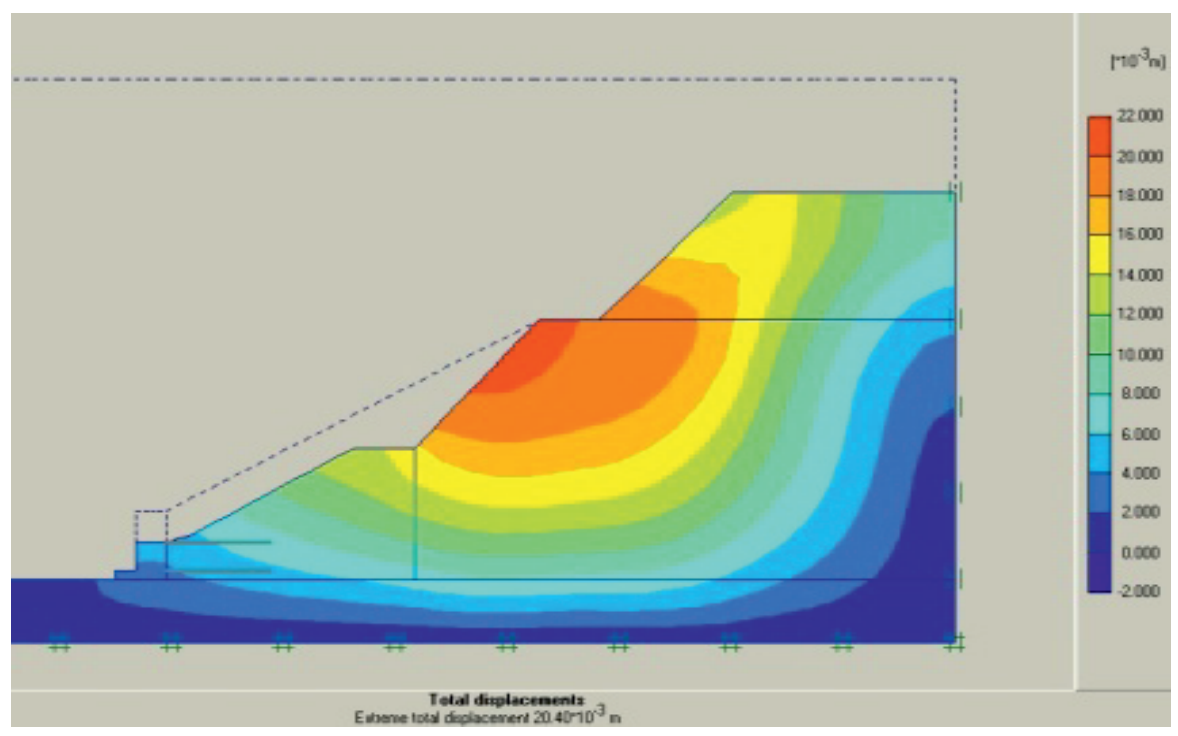

Figure 1c: Numerical Modelling

\subsection{Laboratory Experiment}

Laboratory experiments can be standard testing methods, independently developed procedures or laboratory scale model investigations (Figure 2a). Standard testing methods such as according to BS or ASTM or other established standards, are commonly used to test materials and systems to be used in or related to the research or investigation. In engineering and built environment, these can be strength, environmental and durability tests such as tensile (ASTM, BS), water quality (APHA) and water absorption (ASTM, BS). The standard tests are usually used to gather preliminary data on the material to be used in model testing or field experiments. In the case of numerical or computer modelling, data and results from standard laboratory tests can be used as the specific data input for the model. For example, in a computer structural model, data on material properties such as strength, modulus and dimensions are required. These data has to be established or ready before computer numerical model investigation can proceed [3]. 
Scientific research is about discovery of new things, methods, systems or theories. It is almost inevitable that in the course of most experimental research, a researcher will have to come up with one or more independent procedures that can be calibrated and repeated. The procedure can be a very simple one or a very complicated one. It could be just a small portion of the investigation or it could also be the major procedure for the research. In this case, data and discussion on repeatability and measurement uncertainty must be provided in the research report or thesis.

Laboratory scale model is a small scale, physical model of a larger actual or prototype structure or systems. It is constructed in a laboratory and tested under controlled and monitored conditions. The advantages of small scale models can be their benefits in terms of controllable varied loading conditions, observable effect of extreme/failure loading conditions, and the minimum cost of construction [4].

However, scale models have other issues to be considered such as boundary conditions and similitude. Similitude is the scaling effect of multiple variants such as dimensional, force, time, boundary and instrumentation. Fortunately, there exists established theoretical bases for scaling factors for various conditions. In a simple laboratory scale model for parametric study, only the dimensional similitude and boundary conditions are usually considered (Figure 2b).

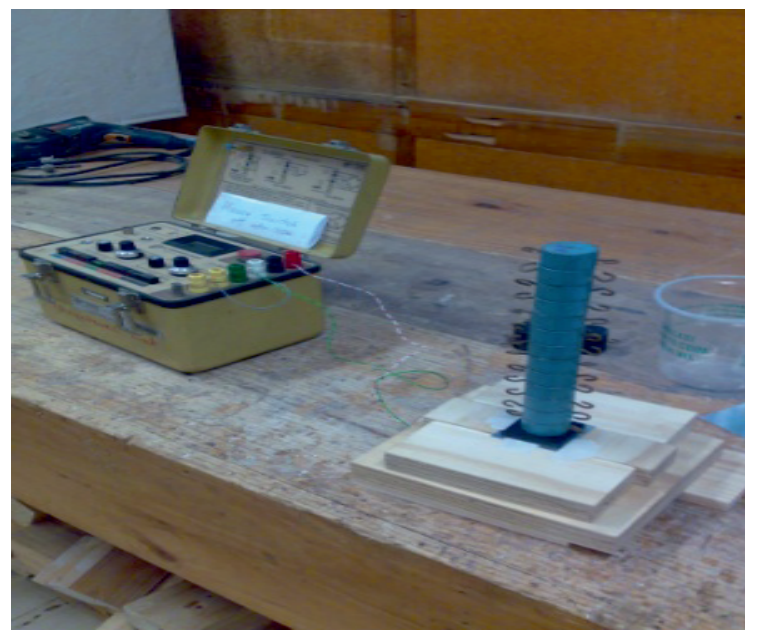

Figure 2a: Special new simple procedure for calibration of new pressure sensor

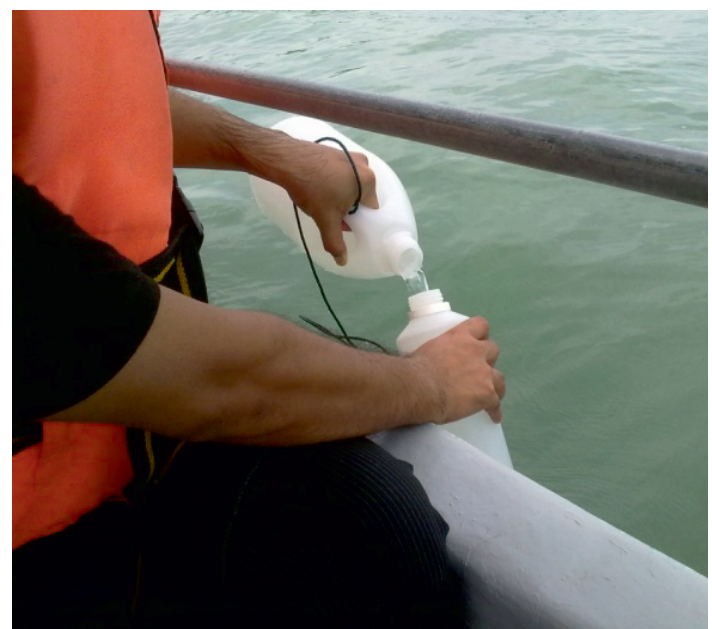

Figure 2b: Marine water sampling for standard water quality test such as BOD, COD, DO, nitrate etc.

\subsection{Field Experiments}

Experiments carried out in the field require careful planning and coordination. Higher contingencies in terms of budget and time must be considered. Controlling and monitoring the changing parameters on site could also involve other parties and the law. Security of instrumentation must be taken seriously.

As with other experiments, the purpose of field experiment is to collect data for the research. In the field, it could be harder to control or to limit the various influences from natural conditions. For example, if one is dealing with the ground, the variation in water table is hard to control because the water movement in soil extend to distance locations - something that could not be controlled but can only be observed is still research - but not considered experimental research. Astronomers study the sky by observation.

What is happening in the sky cannot be controlled; it can only be observed. Based on observation, scientist and researchers will be able to make some conclusion and theories. Therefore, it is important for researchers to differentiate between observation and experiment data collection methods. 


\subsection{Computer Numerical Model}

Computer numerical model is another method to carry out experiments (Figure 3). Presently there are various computer codes that can be utilized to construct a model. One of them is Finite Element Code (FEM). A code is basically an assembly of FEM instructions that has been pre-programmed to do certain things. Another popular code in engineering investigations is the CFD (Computational Fluid Dynamic) code.

In the past, researchers had to be able to write their own FEM or CFD program in order to construct a computer numerical model of their investigation. Fortunately today, some codes are packaged into software that can be utilized to construct a model. There is usually a component in the software called "modeller". Researchers will be able to build their experimental model and test with various conditions related to the research. However, some researchers still prefer to write their own code because it will allow more freedom of decision in their experimentation. Nevertheless, the availability of packaged software enables researchers to focus on experiments instead of writing programs [5].

Using the FEM or CFD code to construct a model, a researcher will be able to control the various input parameters and study the output - the cause and effect. In this case, the quality and accuracy of the output or data or observation is as good as the input data. In most computer numerical modelling, a realistic input data must first be obtained from laboratory testing of the material involved in the studies. The model must also be calibrated against known or previously recorded events or cases.
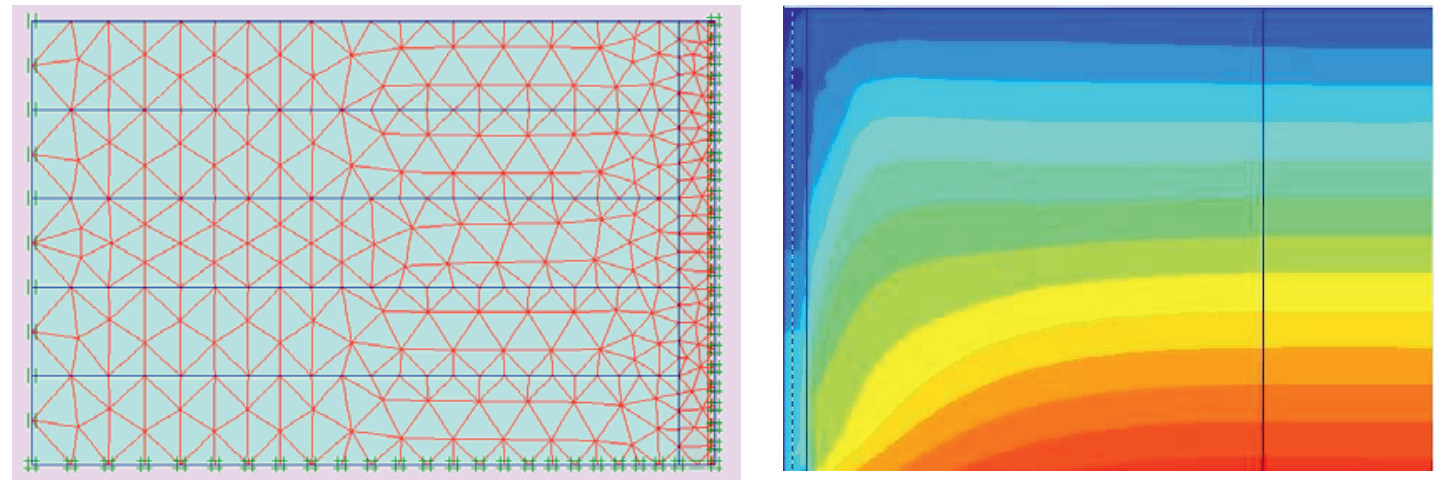

Figure 3: FEM mesh and output for studies of soil and a retaining structure

\section{Data Collection}

Experiments are carried out for researchers to collect data. These data then can be analysed or processed to produce meaningful conclusions. There are four major ways to collect data: surveys, observation, computer simulation and experiment. In addition to laboratory and field experiments, this paper considers computer model simulation as an experiment. Other computer simulation can be statistical; 2D/3D vector/scalar/graphical; and binary [4].

This section will further discuss the method of collecting data from experiments in the area of engineering and built environment. In experiments, one or more independent variables can be changed and the outcome is recorded. If the independent variable cannot be controlled, it is not an experiment instead it is an observation (although it is still the act of collecting data) as discussed before.

\subsection{Instrumentation and Sensors}

Instrumentation is a system used to control, measure and transmit information or data during the experimentation. Typical instrumentations include hardware for transducers and software for data 
processing and storage. A transducer is a device that converts a physical parameter sensed by its sensor into an analogue electrical signal. Some common transducers and their applications are described in the following table [5].

Table 1: Common transducers in built environment research applications

\begin{tabular}{|c|l|}
\hline Transducers & \multicolumn{1}{c|}{ Description } \\
\hline Strain gage & $\begin{array}{l}\text { This is the most basic form of transducer. It operates on the principle of electrical } \\
\text { resistance. It can detect positive or negative strain of the object the gage is } \\
\text { bonded to. It can be bonded to metal, concrete, plastic etc. It can be used to } \\
\text { construct other type of transducers such as load cell, pressure cell etc. }\end{array}$ \\
\hline $\begin{array}{c}\text { LDVT } \\
\text { (Linear Displacement } \\
\text { Variable Transducer) }\end{array}$ & $\begin{array}{l}\text { LDVT can be used to measure displacement or movement of components in the } \\
\text { research relative to its position. This is basically an electronic version of a dial } \\
\text { gage but with more capabilities because the movement can be detected by } \\
\text { computers in a very short time interval. }\end{array}$ \\
\hline Load Cell & $\begin{array}{l}\text { Load cell is used to measure force in tension or compression. Load cell with low } \\
\text { and high range capacity are available for various types of loading. }\end{array}$ \\
\hline Pressure cell & This transducer measures fluid or soil pressure. \\
\hline Temperature & $\begin{array}{l}\text { This is usually a stand-alone transducer. But in specific research that requires } \\
\text { measurement of temperature or heat continuously, it can be connected to a data } \\
\text { logging system. }\end{array}$ \\
\hline Accelerometer & $\begin{array}{l}\text { Accelerometer measures acceleration with respect to gravity (g). This is } \\
\text { commonly used in research related to vibration, earthquake, impact, blast and } \\
\text { speed. }\end{array}$ \\
\hline Piezometer & $\begin{array}{l}\text { Piezometer is used to measure liquid or water pressure underground in the field. } \\
\text { It utilizes pneumatic or strain gage systems. Vibrating wire (VW) piezometer is } \\
\text { more popular now for pore water pressure. }\end{array}$ \\
\hline Sound meter & Measures level of environmental noise \\
\hline Light meter & Measures light intensity \\
\hline
\end{tabular}

\subsection{Data Logging}

Transducers described above produce analogue electrical signals that need to be converted to a digital signal for it to be able to be used in digital computer processing. This can be done through the use of specialized hardware and software called a data logger. In some situations, if the analogue signal is too small or too noisy, it has to go through another piece of hardware called an amplifier to be filtered and amplified first $[3,4]$.

There are two general classes of data logger. One is the static data logger and the other one is the dynamic data logger. The choice of use depends on the type and quality of data required. If the required data is very sensitive to time such as impact, vibration and other high-speed phenomena, the dynamic data logger is required. The static data logger is sufficient for tests such as load, pressure and temperature tests. The data capture interval for a static data logger is usually only up to one second interval. However, in the case of dynamic data logger the interval can be set to micro or nano seconds (usually in terms of hertz i.e. $1000 \mathrm{hz}, 5000 \mathrm{hz}$ or $25000 \mathrm{hz}$ - cycles per second).

\section{Conclusions}

To experiment is to try to look for and to confirm quantitatively. Experimental research in engineering and built environment requires specific instrumentation to control, predict and measure the cause and effect. The researcher must be able to know what kind of qualities and properties are to be measured and can be measured with current existing technology. Then, the experiment can be done in the laboratory, in the field or using computer models or a combination of these. 


\section{Acknowledgement}

The author would like to thank Dr Kwan Wai Hoe, Adhilla Ainun Musir and Abadini Integras Engineers Sdn Bhd for providing pictures to be included in this paper

\section{References}

1. Lab General, A brief introduction to civil engineering labs, SIUE Department of Civil Engineering., 2001

2. L.Y. Hong, Research methods in engineering and science, Curtin University of Technology, Australia, 2005

3. H. Krawinkler, B. Zhu, US/PRC Workshop on experimental methods in earthquake engineering, EEC, Stanford University, 1993

4. K. Srinagesh, Principles of Experimental Research, Butterworth-Heinemann, 2009. pp: 9-17

5. D. Thiel, Research methods in electrical engineering, Griffith University, Brisbane , Australia, 2009 